\title{
Der Placeboeffekt
}

Gar wütend tobt der Krieg der Medizin-Giganten.

Ein jeder weiss das Recht auf seiner Seite, und beide fühlen sich allein als Heilsgaranten, unwissend, dass dies Pferd sie in die Pleite reite.

Nur was die Schule lehrt, was doppelt blind bewiesen, was Evidenz basiert, ist Rechtens und zu brauchen. Was andres ist schon à priori zu vermiesen. Sie schwören auf dies eine bis die Köpfe rauchen.

Den andern ist die Empirie vor allem wichtig, denn was von Basel kommt, ist Gift und zu verdammen. Nur Bio, Nadeln, Kräuter, Bölleli allein sind richtig, denn so sind Körper, Geist und Seele gut beisammen.

Die Ersten fordern wissenschaftlich reine Studien, die Zweiten weisen tolle Resultate vor, die Ersten lehnen ab und nennens Luginen, die Zweiten werfen Fehlen der Gesamtsicht vor.
Doch beide kämpfen nicht, weil sie sich tödlich hassen.

Nein, beide wollen, dass sie Ja, die Andern Nein, den garantierten Lohn der Arbeit von den Kassen erhalten. Sind die Argumente nur zum Schein?

Wir hoffen nicht, nur dass Patient und Heilung bei Beiden über ihrem Kampfgetöse stehen, und dass sie einverstanden wären mit der Teilung falls Argumente kämen, welche einzusehen.

Die Ersten setzen in den doppelt-blinden Testen Placebo ein und nennen den Erfolg Effekt.

Die Zweiten wissen, dass zur Heilung aller Bresten die Seele, sprich Placebo, Körperwelt abdeckt.

Drum rat ich, singt im Chor: «Placebo sei gelobt!», denn Beiden hilft es weiter zum Erhalt von Leben. So hätte ohne Sinn und Zweck der Kampf getobt. Nur Couchepin müsste man Placebo-Stunden geben.

Dr. med. Wolf Zimmerli, Oberdiessbach

Illustration aus:

Honoré Daumier, 240 Lithographien, ausgewählt und eingeleitet von Wilhelm Wartmann. Birsfelden/Basel: Schibli-Doppler. S. 52. Wiedergabe mit freundlicher Genehmigung des Verlags.

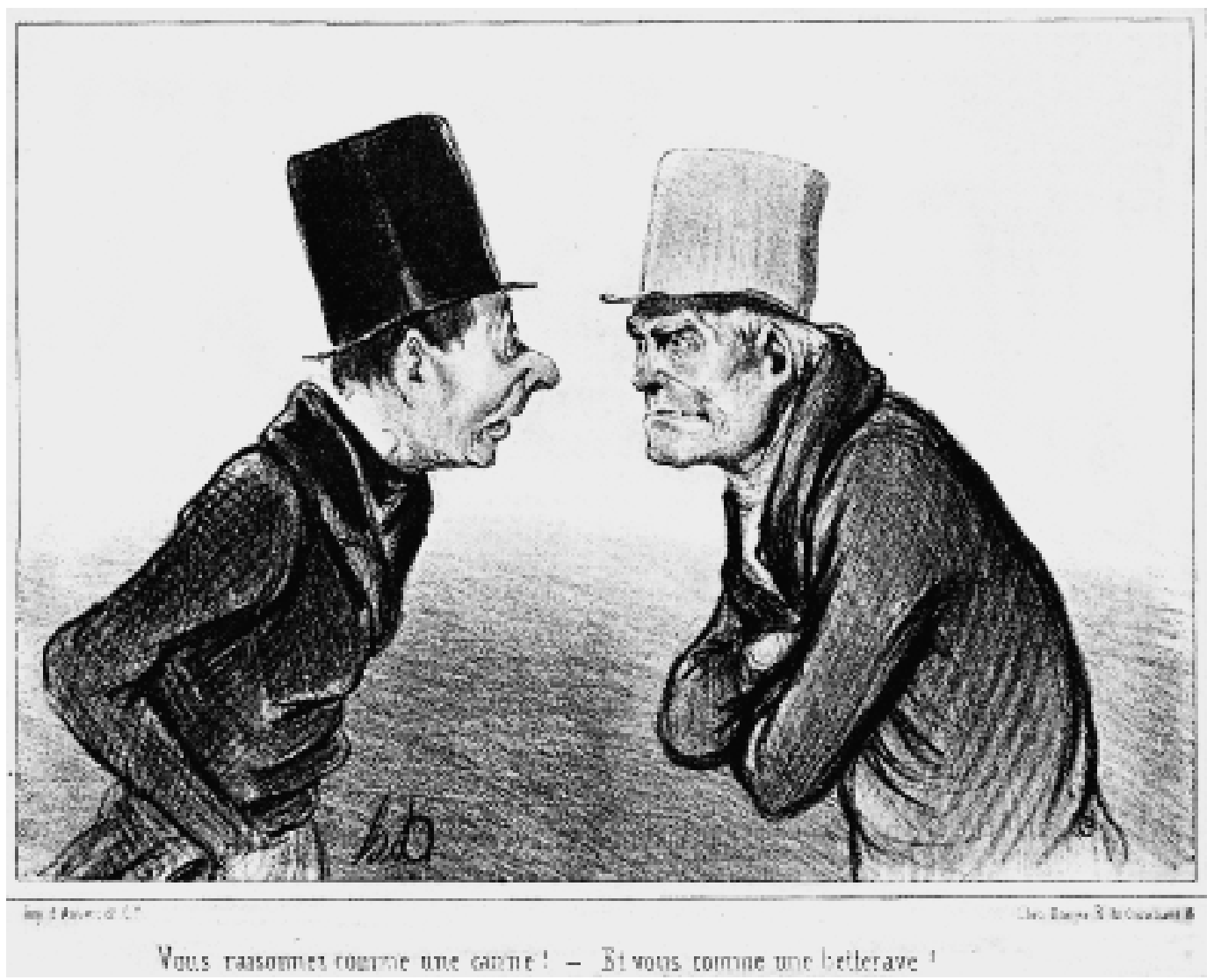

